\title{
The influence of the centre bow and wet-deck geometry on motions of wave piercing catamarans
}

\author{
Babak Shabani ${ }^{1 *}$, Jason Lavroff ${ }^{1}$, Damien S Holloway ${ }^{1}$, Michael R Davis ${ }^{1}$ and Giles A Thomas ${ }^{2}$ \\ ${ }^{1}$ School of Engineering and ICT, University of Tasmania, Australia \\ ${ }^{2}$ Department of Mechanical Engineering, University College London, UK \\ * Corresponding author, Email: babak.shabani@utas.edu.au
}

\section{Keywords}

Maritime systems: research/ design/ development, high speed catamaran, centre bow geometry, wet-deck height, motion response, heave, pitch, relative motion, slamming

\begin{abstract}
The effects of tunnel height and centre bow length on the motions of a $112 \mathrm{~m}$ wave piercer catamaran with an above water centre bow were investigated through model tests. Five alternative centre bow configurations were considered, and multiple series of model tests were conducted in regular head sea waves. The results showed that both heave and pitch increased over a wide range of wave encounter frequency as the wet-deck height of the catamaran model increased. However, increasing the length of the centre bow showed an increase in the pitch but a decrease in the heave for a limited range of wave encounter frequency near the heave and pitch resonance frequencies of the catamaran model. The positions of minimum vertical displacement were found to be aft of the longitudinal centre of gravity, between $20 \%$ and $38 \%$ of the overall length from the transom.
\end{abstract}


Increase in wet-deck height and consequently the archway clearance between the main hulls and centre bow also resulted in an increase in vertical displacement relative to the undisturbed water surface in the centre bow area. The results also indicated the vulnerability to wet-deck slamming for the different bow and wet-deck designs.

\section{Introduction}

Large wave piercing catamarans (WPCs) with an above water centre bow have the capability of satisfying economic demands for fast sea transportation. Being operated mainly as passenger/car ferries with a high payload capacity, these vessels have shown superior seakeeping qualities compared to conventional catamarans because of the influence of the centre bow located between the two demihulls as shown in Figure 1. In this paper, the effects of the centre bow length and wetdeck height/tunnel clearance on the motions of a $112 \mathrm{~m}$ wave piercing catamaran built by Incat Tasmania (Figure 1) are investigated. In addition, attention is paid to vertical motions and the relative displacement along the model length to evaluate the performance of different wet-deck configurations regarding vulnerability to slamming.

The main demi-hulls of an Incat catamaran have a narrowed forward profile and feature high bow slenderness with no bow flare above the waterline. This hull design enables high speeds to be achieved and also reduces the hull-wave interaction in the bow area. Generally, the motions of a wave piercer twin-hull vessel are not as severe in waves as the motion of catamarans with conventional hull forms since reserve buoyancy in the bow area is provided by the centre bow which is above the calm water line. A wave piercer vessel is therefore expected to have less response in waves and better performance at high speeds. A less sensitive response to waves is usually 
achievable in twin hulls by increasing the breadth/length ratio and reducing the water plane area to some extent. $^{1}$

Fang and $\mathrm{Chan}^{2}$ compared a medium size WPC with a flat wet-deck traditional catamaran and showed that the wave piercer form had better seakeeping characteristics, especially in oblique waves, and that the flat wet-deck design showed a tendency to deck dive in following seas. The centre bow in Incat WPC vessels can however interact with the passage of larger waves through the tunnel between demi-hulls and thus does influence motions to some degree, although motions are generally less than conventional catamarans. The centre bow effect on motions is nonlinear, and its contribution to the seakeeping characteristics of catamarans has not been extensively investigated. ${ }^{3,}$ 4

The primary role of the centre bow in WPCs is to provide additional reserve buoyancy to minimise the risk of deck diving in following seas. ${ }^{5,6}$ The length of the centre bow is the main geometrical parameter for controlling the reserve buoyancy in waves. The longer the centre bow, the more reserve buoyancy in the forward area and thus deck diving can be significantly reduced or completely avoided. However, the centre bow entry in waves adds extra complexity and nonlinearity in the hull interaction with waves due to arch filling and slamming. ${ }^{7,8}$ The centre bow configuration, as shown in Figure 1 divides the forward area between the demihulls into two regions, here termed "archways". Both motions and structural loads of WPCs with a centre bow are influenced to some degree by the centre bow depth of immersion. Extreme nonlinearity in the loads and motions, however, arises when the archways are filled with water. Arch closure occurs when the centre bow immersion increases to a certain level during pitch-in motion when the water displaced by the centre bow and the demihulls fill the arch gaps. ${ }^{9}$ 
Since the primary design concern of the arch filling is the occurrence of large transient slam loads on the cross wet-deck structure between the centre bow and demihulls, the wet-deck height becomes another important design parameter for the centre bow design as the wet-deck height consequently affects the archway clearance.

Lavroff and Davis ${ }^{9}$ and Lavroff et al. ${ }^{6}$ tested a $2.5 \mathrm{~m}$ long, segmented hydro-elastic catamaran model of the INCAT $112 \mathrm{~m}$ design and showed that both heave and pitch motions and accelerations increased significantly as the model speed increased in regular waves in head seas. This study indicated that the wave height also affected the dimensionless heave amplitude at wave encounter frequencies near the heave resonance encounter frequency, while the dimensionless pitch was affected less by the wave height but over a broader range of frequency. Since the centre bow configuration influences the centre bow entry force and thus the hull motion, any adverse effect on the motions caused by changing the centre bow design is not easily predicted at the preliminary design stage. This is an important consideration when designing a vessel to best suit the proposed ship operational conditions.

Limited investigations regarding the effect of bow length and wet-deck on the motions of WPCs have been conducted to date. Shahraki et al. ${ }^{10}$ reported the variations of the heave and pitch amplitude for different centre bow lengths and wet-deck heights each for a single speed and moderate wave height. In the present investigation a broader range of test conditions is investigated for various forward speeds. The motion analyses are also extended here to determine the minimum tunnel clearance to avoid water impact on the wet-deck for the various centre bow configurations considered. In particular the effect of variations in centre bow height and length are explained and the motion response is discussed for the various test conditions investigated. The results from the present investigation thus provide a fuller insight on the influence of the centre bow configuration 
on the motion response that can be used a basis for future designs at higher speeds and in larger seas. The occurrence of slamming and consequent whipping responses will often influence the decision of a ship captain to change speed and course and consequently global ship motions will also be changed and slamming alleviated. In the tests conducted here the aim has been to explore the most severe extreme slamming possible. However, it is unlikely that such extreme conditions would be encountered in normal commercial ship operation although in military operations severe slamming is more likely to occur.

\section{Model set-up and test facilities}

\section{Segmented catamaran model}

A $2.5 \mathrm{~m}$ long hydro-elastic scale model of the $112 \mathrm{~m}$ Incat wave piercing catamaran was used in the tank test investigation ${ }^{10}$. Table 1 provides the specifications of the model and the full-scale vessel, and Figure 2 shows a photograph of the catamaran model. The model consisted of forward, middle and aft segments connected by flexible links as shown in Figure 3. It has been found in model impulse excitation tests in calm water ${ }^{6,11}$ that the frequency of the first longitudinal whipping mode is not significantly affected by forward speed and that the damping ratio increases from approximately 0.02 to 0.05 as model Froude number increases from zero to 0.6 . The first mode frequency of the model was tuned by adjustment of the stiffness segment connecting links to a value of $13.7 \mathrm{~Hz}$ simulating a full scale whipping mode at $2.1 \mathrm{~Hz}$. The damping ratio was similar to that observed for full scale vessels ${ }^{8}$. 
Table 1. Specifications of the model and full-scale catamaran vessel.

\begin{tabular}{lll}
\hline Description & Model & Full scale \\
\hline Overall length (LOA) & $2.5 \mathrm{~m}$ & $112.6 \mathrm{~m}$ \\
Water line length & $2.36 \mathrm{~m}$ & $105.6 \mathrm{~m}$ \\
Displacement & $27.12 \mathrm{~kg}$ & 2500 tonnes \\
Overall beam & $0.68 \mathrm{~m}$ & $30.5 \mathrm{~m}$ \\
Beam of hulls & $0.13 \mathrm{~m}$ & $5.8 \mathrm{~m}$ \\
LCG (from transom) & $0.941 \mathrm{~m}$ & $42.15 \mathrm{~m}$ \\
Pitch radius of gyration & $0.69 \mathrm{~m}$ & $30.91 \mathrm{~m}$
\end{tabular}

This model was developed to measure both motions and loads acting on the centre bow and demihulls. Therefore the three segments were connected by flexible links designed both to replicate the first two longitudinal natural frequencies and mode shapes and to serve as bending moment measurement devices via differential strain gauges. ${ }^{3,11}$ It should be noted that, hydroelastic simulation is essential for modelling of the response to slam loads ${ }^{6}$, although in general these impact loads do not have a large effect on global motion of the hull.

\section{Various bow configurations}

The configuration of the model allowed adjustment of the wet-deck height and the length of the centre bow. Five centre bow $(\mathrm{CB})$ configurations were used during experiments, these being designated as the parent, high, low, long and short centre bow. The different bows were tested to investigate the effect of the tunnel clearance and centre bow length on motions of wave piercing catamarans. The parent CB represents the centre bow of the $112 \mathrm{~m}$ INCAT catamaran as shown in 
Figure 1. Figures 4 and 5 show a comparison of the parent, high and low centre bow configurations tested. The tunnel clearance is defined here as the vertical distance of the wet-deck relative to the calm waterline at the centre bow aft end section, and the centre bow length is defined as the longitudinal distance from the centre bow truncation to the foremost bow position (see Figure 4). Table 2 shows the tunnel clearance and centre bow length for the various centre bow configurations.

Table 2. Centre bow design parameters at model scale.

\begin{tabular}{llllll}
\hline Centre bow & High & Parent & Low & Long & Short \\
& & & & & \\
& & & & & \\
Tunnel clearance $(\mathrm{mm})$ & 94 & 67 & 52 & 67 & 67 \\
CB length (mm) & 608 & 608 & 608 & 758 & 458 \\
& & & & & \\
\hline
\end{tabular}

The long, parent and the short centre bows are also shown in Figure 4. The centre bow truncation of the short, long and parent CBs are evident in Figure 4 at approximately 2050, 1900 and $1750 \mathrm{~mm}$ from the model transom. Though they differ in length, they are identical in tunnel clearance $(67 \mathrm{~mm})$. The short CB configuration was obtained by removing $25 \%$ of the parent CB length $(608 \mathrm{~mm}$ ) from its truncation, and the long CB was made by adding an extender which also was $25 \%$ of the parent $C B$ length. No significant change was made in the cross sections of the extender compared to the parent centre bow truncated cross-section. The pitch radii of gyration of the catamaran model with various CB configurations varied only by approximately $0.4 \%$ from that given in Table 1. The mass distributions of the parent and short $C B$ segments were modified to achieve the mass distribution of the long $C B$ by adding extra weight on the centreline of CB segment. 
Figure 5 compares the sectional body lines of the high, parent and low wet-deck at the centre bow truncation. The wet-deck of each design is shown with the horizontal line between the archways. When compared to the parent wet-deck, the low wet-deck has the same keel line but a reduced a tunnel clearance $(52 \mathrm{~mm})$. In contrast, the tunnel clearance of the high wet-deck is $94 \mathrm{~mm}, 1.4$ times the clearance of the parent wet-deck. The high, parent and low wet-decks are equal in length (608 $\mathrm{mm})$.

The keel line of each centre bow is close to the design waterline (DWL), as shown in Figure 5, and thus the centre bow can frequently interact with the water. During the water entry, the centre bow immersion volume gradually increases. However, the centre bow can accelerate the displaced water laterally towards the demihulls hulls. Increasing the vertical position of the centre keel with increasing wet-deck height was not adopted as this reduces the immersion depth and hydrodynamic damping.

The arch top vertical position is above the wet-deck and this aids the water passage through the archways as the water displaced by the centre bow and demihulls raises the water surface elevation inside the archways. In addition, in a two-dimensional drop test study ${ }^{12}$, it was found that locating the arch top transverse positions close to the demihulls help to reduce the water impact pressure underneath the arch structure when the water completely fills the archways.

Figure 6 shows the variations of tunnel clearance $T_{\mathrm{cl}}$, and the centre bow length $L_{\mathrm{cb}}$, normalised by the overall length $L$, for different centre bow designs. The combination of these five configurations creates a design space with the centre bow length extending from approximately $18 \%$ to about $30 \%$ of the overall length and the tunnel clearance in the range between $2 \%$ and $3.8 \%$ of the overall length. As mentioned earlier, while the tunnel clearance in the area of the archways is a crucial 
factor for design against the wet-deck slamming, the volume factor has hydrodynamic importance for the design against deck diving by providing additional hydrodynamic upward force during bow entry into the encountered wave in following seas.

Figure 7 compares the centre bow design volume $\nabla_{\mathrm{cb}}$ (defined as the bow volume below the wetdeck level) normalised by the displacement of the catamaran $\nabla$, as a function of the normalised centre bow length. As shown, the centre bow volume was increased linearly from $1.44 \%$ to $7.64 \%$ of the model displaced volume by the increase of centre bow length. Despite the significance difference in the wet-deck height, the design volume of the low wet-deck was kept the same as the parent wet-deck to avoid a reduction in the centre bow reserve buoyancy. The high wet-deck, however, had potential for increasing the reserve buoyancy and thus the high wet-deck design volume was set to almost 1.9 times the design volume of the parent $\mathrm{CB}$.

\section{Model test conditions}

Model tests were performed in the Australian Maritime College towing tank. The water depth was set to $1.4 \mathrm{~m}$ for the tank, which is $100 \mathrm{~m}$ long and $3.55 \mathrm{~m}$ width. A single paddle wave maker is located at the far end of the tank from the model start position. The model was towed in the towing tank via two posts and was free to move in pitch and heave. Vertical displacements were measured at the two towing posts attached to the middle and aft segments by using two Linear Variable Differential Transducers (LVDTs). The data from LVDTs were then used to calculate the heave and pitch at the LCG. A stationary wave probe with a twin-wire resistive type sensor was located in front of the wavemaker at a distance of approximately $9 \mathrm{~m}$ to measure the wave height and frequency before commencing a test run of the model attached to the carriage. The model test conditions are 
given in Table 3 for regular waves in head seas. Multiple wave frequencies were selected for each of the two test conditions.

Table 3. Model test conditions.

\begin{tabular}{cccccc}
\hline & & \multicolumn{2}{c}{ Model scale } & \multicolumn{2}{c}{ Full-scale } \\
\hline & Wetted length & Velocity & Wave height & Velocity & Wave height \\
& & & & & \\
\\
Froude number & & $V_{m}(\mathrm{~m} / \mathrm{s})$ & $h_{w}(\mathrm{~mm})$ & $V_{s}(\mathrm{knots})$ & $H(\mathrm{~m})$ \\
Condition 1 & 0.32 & 1.53 & 60 & 20 & 2.7 \\
\hline
\end{tabular}

\section{Testing procedure in waves}

The elevations of wave peaks and troughs collected from the static wave measurement showed there was some level of variability in the measurements. The variability of wave peaks and troughs in each single run was considered as a random error, and the $95 \%$ confidence interval of the mean peaks and troughs were calculated to estimate these variabilities. Bias error was not included in the uncertainty analysis. The variability of the wave height was estimated by using error propagation rules. Generally, the variability of the average wave height increased as the wave frequency decreased.

To provide an overview of the average wave height obtained by the stationary wave probe during the catamaran model tests at different conditions, one can define a dimensionless average wave 
height $\left(\bar{h}_{w}^{*}\right)$ as the experimentally obtained value $\left(\bar{h}_{w, \text { measured }}\right)$ divided by the nominal wave height $\left(h_{w, \text { nominal }}\right)$ expected at each run,

$$
\bar{h}_{w}^{*}=\frac{\bar{h}_{w, \text { measured }}}{h_{w, \text { nominal }}}
$$

Figure 8 shows a density histogram of dimensionless average wave height obtained for the present work. We can see that a normal distribution with mean $\mu=0.995$ and standard deviation $\sigma=0.0385$ provides a good fit to the population of the dimensionless average wave height. Therefore, it can be estimated that $95 \%$ of the measured average wave heights lie within $h_{w, \text { nominal }} \times(\mu \pm 2 \sigma)$ as it has a normal distribution.

To provide an overview of the observed variability in the measurement of the average wave height $\left(\bar{h}_{w}\right)$, the coefficient of variation $\left(C V_{\bar{h}_{w}}\right)$ of the average wave height would be an appropriate indicator. The coefficient of variation is defined as the ratio of the standard deviation of the sample to the mean value of the sample. Therefore,

$$
C V_{\bar{h}_{w}}=\frac{S_{\bar{h}_{w}}}{\bar{h}_{w}}
$$

where, $S_{\bar{h}_{w}}$ is the standard deviation of the average wave height.

Figure 9 shows a density histogram of the coefficient of variation of average wave height. The histogram would be estimated by a lognormal probability density function as shown. A lognormal distribution of $\mathrm{CV}$ means that the natural logarithmic value of $\mathrm{CV}$ has a normal distribution. 
The cumulative distribution function of the fitted distribution showed that the CV of the average wave height was less than 0.01 for $50 \%$ of the total runs and less than 0.0315 for $95 \%$ of the total population.

Two resistive type wave probes were also used in the experiments as moving wave gauges. One was aligned longitudinally with the catamaran model LCG and the other one was placed at approximately $1 \mathrm{~m}$ forward of the LCG with transverse distances of $1.4 \mathrm{~m}$ from the centre line of the catamaran model. The forward probe was located on the starboard side whereas the LCG probe was located on the port side.

Although the contactable probes are commonly used for wave measurement, they are not appropriate to accurately measure moving surface elevations at high speeds. The moving wave probes had a slim backbone structure to support the twin wire sensors. These immersed parts, however, created unwanted disturbances on the surface level in the form of water pile up in the front and ventilation at the back. For these reasons, the resistive probes gave poor wave height measurements. However, reliable phase values were achieved with the moving probes that were beneficial for the purposes of this investigation.

To undertake the relative motion analyses, it was required to use the instantaneous wave profile correctly. The encountered wave profiles measured by the moving probes had a significant error in the mean level and amplitude. The range of variability in peaks and troughs in moving wave measurements was greater than that in static wave measurements. The moving wave probe signals were therefore corrected in amplitude on the basis of the more accurate data collected by the stationary wave probe. The procedure involved the elimination of the mean level trend and the correction of the average amplitude but not the variability of peaks and troughs. 
Figure 10 summarises the catamaran model heave and pitch peaks in $60 \mathrm{~mm}$ waves at a speed of $1.53 \mathrm{~m} / \mathrm{s}$ as a function of wave encounter frequency. Each test run is presented as a category. Hence there are duplicates and the encounter frequencies are not equally spread. The wave encounter frequencies $\left(\omega_{\mathrm{e}}\right)$ are presented in a non-dimensional form (i. e. $\left.\omega_{\mathrm{e}}^{*}=\omega_{\mathrm{e}} \sqrt{\frac{\mathrm{L}_{\mathrm{m}}}{\mathrm{g}}}\right)$, where $\omega_{\mathrm{e}}^{*}$ is the dimensionless wave encounter frequency, $\mathrm{L}_{\mathrm{m}}$ is the model length and $\mathrm{g}$ is gravitational acceleration. The solid line and the circle inside each box present the median and mean peak magnitudes, respectively. The box shows 25 th to 75 th percentiles in the peaks found at each dimensionless wave encounter frequency, and the whiskers show the peak range.

In general, the range of variability of the heave and pitch was wider in the low and high frequency ranges compared to the middle frequency range. The variability trend in the motion responses over the low range of encounter wave frequency was likely associated with the wave irregularities, whereas it was rather related to the response irregularities within the high-frequency wave tests. This can be explained, for instance, by considering the measured wave profiles and heave responses. The heave in the low frequency range (i.e. long waves) followed the encountered wave profile where the variability in measured wave peaks and trough was much higher over the low frequency range compared to that observed within the high-frequency wave tests. However, the heave responses had relatively strong harmonic distortions within the high-frequency wave tests as opposed to that observed for encountered wave profiles.

A few wave frequencies were also selected to evaluate the repeatability of the results at conditions in which maximum pitch or heave amplitudes were observed. Examples of the repeatability of the 
heave and pitch are shown in Figure 10 at $\omega_{\mathrm{e}}^{*}=3.7$. The results showed a consistency among the repeated tests not only for the mean wave height but also for the range of variability.

\section{Catamaran model motions}

\section{Response Amplitude Operators (RAOs)}

Figures 11 and 12 show the heave and pitch Response Amplitude Operators (RAOs) of various CB configurations at $1.53 \mathrm{~m} / \mathrm{s}$ and $2.89 \mathrm{~m} / \mathrm{s}$. The RAOs of the high, parent and low wet-decks are compared on the left, and the RAOs of the long, parent and short CBs are compared on the right. The error bars show the $95 \%$ confidence intervals of dimensionless heave and pitch within a single run. Dimensionless heave $\left(H^{*}\right)$ and pitch $\left(P^{*}\right)$ are $H^{*}=\frac{\bar{H}_{\mathrm{a}}}{\bar{\zeta}_{\mathrm{a}}}$ and $P^{*}=\frac{\bar{\theta}_{\mathrm{a}}}{\frac{2 \pi \bar{\zeta}_{\mathrm{a}}}{\lambda}}$, where, $\bar{H}_{\mathrm{a}}$ and $\bar{\theta}_{\mathrm{a}}$ are the average heave and pitch amplitudes, and $\frac{2 \pi \bar{\zeta}_{a}}{\lambda}$ is the maximum wave slope defined as a function of average wave amplitude $\left(\bar{\zeta}_{\mathrm{a}}\right)$ and wavelength $(\lambda)$. The variation of wavelength $\lambda$ to model length $L_{m}$ ratio $\left(\lambda / L_{m}\right)$ with respect to non-dimensional encounter frequency $\omega_{e}^{*}$, is also shown in the second $x$ axis.

The ITTC method ${ }^{13}$ of uncertainty analysis, which is based on error propagation rules, was used to calculate the confidence intervals. Generally the uncertainty in the motion RAOs increased with the increase of the forward speed. Further analysis showed that both dimensionless heave and pitch had approximately about \pm 0.03 and \pm 0.01 confidence bounds at the top and low speeds respectively, noting that these values represent approximately the median confidence intervals in the RAOs. 
It can be seen that increasing the wet-deck height increased the heave and pitch motions for the majority of wave frequencies tested. As shown in Figure 11 (c), there is a notable change in the maximum heave between the parent wet-deck and high wet-deck at the top speed.

At the low speed, as shown in Figure 11 (a), the high wet-deck responded with a lower heave amplitude than the parent wet-deck at encounter frequencies in the range $3 \leq \omega_{e}^{*} \leq 4$. This is probably due to the effect of centre bow volume with the high wet-deck rather than the effect of the wet-deck height itself as the centre bow volume is higher in the high wet-deck compared to that of the parent wet-deck. This is because the bow volume is defined for the region below the wet-deck and because the bow keels are always at the calm waterline.

It can be seen in Figure 11 ( $b$ \& d) that increasing the centre bow length decreases the heave in waves longer than the model length. The heave response with the short $C B$ tends to be greater than the parent and long $\mathrm{CB}$ in the range $3 \leq \omega_{e}^{*} \leq 4$. This is more evident at the low speed than at the high speed. As shown in Figure 11 (b), the difference between the short CB and long CB is quite significant at $\omega_{e}^{*}=3.5$ in $60 \mathrm{~mm}$ waves at $1.53 \mathrm{~m} / \mathrm{s}$, where the long CB has approximately $40 \%$ lower heave. Since the short centre bow has a lower volume than the parent $C B$, the results support a hypothesis that the increase in heave amplitude can be attributed to the reduction of the centre bow volume.

The effect of the centre bow length on the pitch is shown in Figure 12 (b \& d). From these results, it can be seen that the centre bow length has little effect on the pitch at the low speed. The difference in pitch between the long $C B$ and parent $C B$ at the top speed is also very small. However, the pitch amplitude of the short $C B$ is significantly lower than the pitch amplitude of the parent $C B$ in the range $3 \leq \omega_{e}^{*} \leq 4$ at the top speed. 
The influence of Froude dependent nonlinearity associated with the centre bow entry on the heave and pitch amplitudes is quite evident within the frequency range $3 \leq \omega_{e}^{*} \leq 4$. This nonlinearity arises primarily because the hulls and bow are not wall sided at the waterline. Therefore, as the hulls and bow experience variable immersion in waves the response to waves is not linear with wave height. The effect is dependent also on the Froude number which characterises the hydrodynamics of the hull interaction with the encountered waves. For instance, the high wet-deck, in this frequency range, showed lower heave amplitude than the parent wet-deck at the low speed, whereas it showed higher heave amplitude at the top speed compared to the parent CB. The short $\mathrm{CB}$, also within the range $3 \leq \omega_{e}^{*} \leq 4$, showed lower pitch amplitude than the parent $\mathrm{CB}$ at the top speed, while there was no significant difference between them at the low speed.

The overall range of heave and pitch 'resonant' dimensionless encounter frequencies (i.e. frequency of maximum response) is located in the range $3 \leq \omega_{\mathrm{e}}^{*} \leq 4$. The resonant heave frequencies are higher than the resonant pitch frequencies. The high wet-deck and short CB configurations had the highest and the lowest resonant encounter frequencies in heave at various wave heights and for both low and top speeds. It appears that the resonant encounter frequencies in heave and pitch increase with the increase of centre bow volume as the high and long CBs have high centre bow volumes. This seems a reasonable outcome as the larger volume would increase the system stiffness.

\section{Heave and pitch phase lag}

Data recorded by the LCG moving wave probe were used to calculate the phase of the heave and pitch with respect to wave elevation at the LCG. Assuming the heave and pitch of the model in regular waves to be sinusoidal, the motions are 


$$
\begin{gathered}
H(t)=H_{a} \cos \left(\omega_{e}\left(t-\Delta t_{h}\right)\right) \\
\theta(t)=\theta_{a} \cos \left(\omega_{e}\left(t-\Delta t_{p}\right)\right)
\end{gathered}
$$

where, $H(t)$ and $\theta(t)$ are the heave and pitch responses, $H_{a}$ and $\theta_{a}$ are the amplitudes of the heave and pitch motions, $\omega_{e}$ is the wave encounter angular frequency, $\Delta t_{h}$ and $\Delta t_{p}$ are the heave and pitch time lags relative to the wave elevation at the LCG.

The relationship between the phase lag $(\phi)$ and the time lag $(\Delta t)$ is

$$
\phi=\omega_{e} \Delta t
$$

The heave or pitch time lag in each single run was determined by a cross-correlation analysis using Matlab (Mathworks, Natick, Massachusetts).

Figures 13 and 14 summarise the heave and pitch phase relative to wave elevations at the LCG of the catamaran model for the different bow configurations. As can be seen, the effects of the tunnel height and bow length on the heave phase responses appear to be relatively small over the majority of tested wave frequencies. The overall trend in heave phase is almost consistent in longer waves. The trends show that the heave tends to remain in phase in the range $2 \leq \omega_{\mathrm{e}}^{*} \leq 3.5$. At higher frequencies the heave phase lag increases linearly with frequency as the encounter frequency increases this suggesting that there is a time delay effect present. The results show consistency in the low to medium frequency range in which large motions are expected. However, the heave phase data is more scattered at high wave frequency, where the hull heave motions are relatively small and so phase determination becomes less accurate. 
The pitch phase is shown in Figure 14 and we see that the trends are consistent over the whole range of tested wave frequencies. The pitch phase increases regularly as the wave encounter frequency increases above a dimensionless encounter frequency of approximately 3 . It can be seen that the centre bow and wet-deck configurations have little effect on the pitch phase. The maximum pitch (bow down) lags the encountered wave crest by $90 \circ(\pi / 2)$ for long wavelength ratios of 3.5 or more, and it becomes out of phase with the wave elevation when the wavelength is slightly higher that the model length.

\section{Implications of motion results}

The heave and pitch RAOs established through model testing can be effectively used for important design considerations such as Motion Sickness Incidence (MSI) and wet-deck slamming.

Esteban et al. ${ }^{14}$ presented a frequency domain analysis method for prediction of MSI on ships. The frequency domain procedure considered a sea wave spectrum that is seen by a ship at different speeds and also the vertical acceleration transfer function obtained from the pitch and heave RAOs to calculate the MSI index introduced by O'Hanlon and McCauley ${ }^{15}$. Piscopo and Scamardella $(2015)^{16}$ introduced an overall MSI index for optimising a passenger catamaran configuration. The output from such calculations may then show the centre bow effect in MSI index for wave piercing catamarans at the initial design stage. Ochi and Bonilla-Norat ${ }^{17}$ also presented an analysis method for relative motion along the ship length with a focus on bottom slamming of a monohull. For the work to be presented here the overall motions along the length of hull for different centre bow configurations are to be considered, but the MSIs are beyond the scope of the current investigation as they depend on the encountered sea conditions. Relative motions along the length of the model 
are considered here in order to demonstrate the effect of different wet-deck designs in relation to the motion response and the vulnerability to wet-deck slamming.

The time variations of vertical displacement $\left(Z_{X}(t)\right)$ of an arbitrary point $X$ on the centreline can be calculated using the heave $(H(t))$ and pitch $(\theta(t))$ time records as

$$
Z_{X}(t)=H(t)-\theta(t) \cdot x,
$$

where $x$ is the longitudinal distance (positive forward) of point $X$ from the LCG.

The relative vertical displacement $\left(Z_{X}^{r e l}\right)$ is then

$$
Z_{X}^{r e l}(t)=Z_{X}(t)-\zeta_{X}(t), \quad(6)
$$

where, $\zeta_{X}(t)$ is the wave elevation at longitudinal distance $x$ from the LCG.

In the absence of wave measurement at all positions along the length of the model, the experimentally measured wave elevation at the LCG can be time shifted to obtain the wave elevation at the required position.

The wave elevation $\zeta_{X}(t)$ in regular waves along the model is

$$
\zeta_{X}(t)=\bar{\zeta}_{a} \cos \left(\omega_{e} t-k x\right)
$$

where, $\omega_{e}$ denotes the wave encounter frequency, $k$ is the wavenumber and $x$ is the longitudinal distance (positive forward) from the LCG. The term $k x$ represents the wave phase shift at point $x$.

The distributions of vertical displacement and relative motions along the model were investigated. The vertical displacement and the wave profile for each longitudinal position at each time step were calculated using equations (5) and (7), respectively. Figure 15(a-f) shows the overall catamaran 
model motions within a half cycle of waves at a few running times. The simulation was initiated at $8.44 \mathrm{~s}$, which is the instant at which the minimum relative motion occurred at $90 \%$ of the length from the transom. Thus, as can be seen in the diagram shown in Figure 15(a) the bow is deeply submerged. The water profile is shown as the undisturbed incoming wave, but would obviously be affected by the presence of the model. The amplitude of the motions at this encounter frequency can be clearly observed from Figure 15 in particular at time $t=8.73 \mathrm{~s}$ showing the demihulls exiting the water. Although this encounter frequency is higher than the resonant frequency, it is still indicative of the magnitude of the response compared to the incident wave profile. This has particular implications especially when the centre bow re-enters the water so as to cause complete arch filling and the associated wet-deck slamming. Thus the selection of centre bow is important especially in the design of the vessel according to the proposed operating condition.

Figure 16 shows the distribution of vertical displacement of the catamaran model along the model length with the parent $C B$, calculated for a few tested wave frequencies in test condition $2(2.89 \mathrm{~m} / \mathrm{s}$ forward speed and $60 \mathrm{~mm}$ wave height). Dimensionless vertical displacement is the amplitude of vertical displacement normalised by the wave amplitude. A centre of pitch cannot be exactly defined since heave and pitch motions are not exactly in phase, but there are longitudinal positions in which vertical motions are low, indicating areas with minimum motion discomfort in waves. This position of minimum motion moves forward from approximately $25 \%$ of the hull length to approximately $40 \%$ of the hull length from the stern transoms as the frequency of the encountered wave increases. On this vessel the passenger deck extends somewhat beyond this range of minimum motion location approximately from $5 \%$ to $70 \%$ of length. The vessel LCG is at $38 \%$ of the length from the transom. 
However we see that passengers are not located in positions of very large motion in long waves close to the bow.

As shown in Figure 16, the vertical displacement amplitude is higher than the wave amplitude for the entire length at $\omega_{e}^{*}=3.8$ and 4.5 and nearly so at $\omega_{e}^{*}=3.35$. For $\omega_{e}^{*} \geq 3.81$, the vertical displacement along the length decrease as the encounter wave frequency increases but this is not the case for the vertical acceleration along the length due to the effect of encounter frequency. As shown in Figure 17 the amplitude of vertical acceleration is highest at $\omega_{e}^{*}=4.5$. Whilst the root mean square (RMS) vertical acceleration is important for the determination of the Motion Sickness Index, the MSI depends strongly on the prevailing sea conditions and so we cannot give a general determination of MSI within the scope of the present paper.

Figure 18 shows the vertical displacements for different CB configurations at a dimensionless wave encounter frequency of $\omega_{e}^{*}=4.5$. This encounter frequency was found to correspond with the frequency of most severe slamming loads on Incat catamarans as identified from previous model experiments. ${ }^{18,19}$

The results show that the high wet-deck has higher vertical displacement in the range $20-100 \%$ of the length from transom compared to the parent wet-deck. The vertical displacements are lower with the short and low wet-decks compared to the parent wet-deck. In addition, the position of minimum vertical motion for the high wet-deck is at $20 \%$ of the length from transom compared to $30 \%$ for other bow configurations.

Figure 19 shows the distribution of relative vertical displacement of the catamaran model with the parent $C B$ for a few wave frequencies at a speed of $2.89 \mathrm{~m} / \mathrm{s}$ and in $60 \mathrm{~mm}$ waves. Dimensionless 
relative vertical displacement is the amplitude of relative vertical displacement normalised by the wave amplitude. As can be seen, the amplitudes of relative vertical displacements are significantly lower in the aft and midship sections compared to the forward sections. The amplitude of relative vertical displacement at the transom is less than the wave amplitude at all frequencies shown, while it can be several times higher than the wave amplitude at the bow at some wave frequencies.

In general, the minimum wet-deck clearance at any section should be higher than the absolute amplitude of relative displacement to avoid water impact, assuming zero trim and sinkage. For instance, the flat wet-deck of the parent wet-deck design at model scale is about $67 \mathrm{~mm}$, and thus in $60 \mathrm{~mm}$ waves (i.e. $30 \mathrm{~mm}$ wave amplitude) water impact occurs when the dimensionless amplitude of relative displacement is 2.23 . Therefore, aft wet-deck slamming is not expected, and there is always sufficient clearance from the transom to the mid ship in $60 \mathrm{~mm}$ waves for all wave frequencies. However, from $75 \%$ of overall length from the stern transoms to the bow the hull structure between the demi-hulls of the parent $C B$ is exposed to the wave slamming impact.

Figure 20 compares the amplitude of relative vertical displacement at $\omega_{e}^{*} \cong 4.5$ for different CB configurations along the model length. As can be seen, the long, short and parent CB configurations have very similar relative vertical displacement over the entire length. The low wet-deck also has slightly lower relative displacement compared to that of the parent wet-deck in the forward area.

The high wet-deck has slightly lower relative motion in the aft areas, but it has considerably higher relative motion in the forward areas compared to other configurations. At $60 \%$ and $80 \%$ of the length from the transom, the high wet-deck has respectively 1.32 and 1.3 times higher amplitude in relative displacement compared to the parent wet-deck. This indicates that increasing the tunnel clearance by 1.4 times from the parent wet-deck to the high wet-deck, as presented in Table 2, 
causes an increase in the amplitude of relative motions, and thus slamming occurrences can still be expected.

\section{Conclusions}

Data obtained from model tests in regular head-seas waves were analysed to evaluate the effect of centre bow length and wet-deck height on the motion characteristics of the $112 \mathrm{~m}$ Incat wavepiercing catamaran. Heave and pitch RAOs of five bow configurations, namely the high and low wetdecks, parent, long and short centre bows were compared for different wave heights at two speeds of $1.53 \mathrm{~m} / \mathrm{s}$ and $2.89 \mathrm{~m} / \mathrm{s}$ at model scale or 20 knots and 38 knots equivalent at full-scale. Relative vertical displacements at different longitudinal positions were reconstructed from experimentally obtained vertical motions and by extrapolation of wave profile data measured at the LCG. The amplitude of the relative vertical displacement was used to determine minimum tunnel clearance to avoid water impact on the underside wet-deck structure. It was found that the heave and pitch resonance frequencies for different bow and wet-deck designs were in the range $3 \leq \omega_{e}^{*} \leq 4$. This is not significantly affected by the centre bow configuration.

It was found that the bow design with the high wet-deck vertical position had the highest level of motions in pitch and heave amongst the different bow and wet-deck configurations tested. It is seen that both heave and pitch motions increased as the wet-deck height of the catamaran model with the centre bow increased. Compared to the parent centre bow, the low wet-deck had slightly lower heave and pitch motions, whereas the high wet-deck design had significantly higher heave and pitch motions. 
Increasing the length of the centre bow showed a consistent but marginal increase in the pitch motion at $1.53 \mathrm{~m} / \mathrm{s}$. At the higher speed $(2.89 \mathrm{~m} / \mathrm{s})$, it was found that the short CB had considerably lower pitch compared to the longer centre bow in the high motion zone near the bow. However, the heave motion decreased as the bow length increased in this zone due to increased motion damping.

The heave and pitch phase responses to the wave elevations at the LCG were not significantly affected by the centre bow length or wet-deck height. The heave and pitch phases showed approximately linearly increasing phase lag relative to the encountered wave elevation for dimensionless encounter frequencies above 3 approximately. At low encounter frequency the heave motion was in phase with the wave elevation and the pitch lag was 90 degrees as expected.

The vertical motions along the model length showed that the position of minimum vertical displacements and accelerations were aft of the LCG at between $20 \%$ and $38 \%$ of the model length from the transom. This indicates the most appropriate location for passengers on the vessel to improve passenger comfort.

The relative vertical displacement along the model was seen to be significantly higher in the bow area compared to the stern. The maximum amplitude of the relative vertical displacement obtained in the aft area was slightly above the wave amplitude, this indicating the minimum tunnel clearance above the wave amplitude to avoid water impact on the aft flat wet-deck. It was found that the flat wet-deck approaching the parent centre bow truncation at $76 \%$ of the overall length from the stern transoms is vulnerable to the water impact due to sharp increases in the amplitude of relative motion from midship to the bow. It was also seen that increase in wet-deck and archways clearance resulted in an increase in relative vertical displacement in the centre bow area showing the potential for archway slamming and its effect on vertical motions. 
Overall, lowering the wet-deck/archway clearance did not create a noticeable advantage in the motions while raising it caused disadvantages for both heave and pitch especially at a full speed of 38 knots. The shorter centre bow provided advantages in pitch at certain wave frequencies at full speed, but it also caused some disadvantages in the heave at the lower speed. The longer centre bow provided a consistent advantage in heave for both speeds also at certain frequencies and did not cause a significant change in pitch.

The selection of best centre bow configuration or modification of the parent centre bow requires careful consideration of the vessel's in service operational envelope. From this investigation, it is clear that the improvements for motion can be achieved achieved within certain frequency ranges of the encountered wave spectrum and the selection of an appropriate centre bow can have a beneficial influence on the motion response depending on the sea conditions to be encountered in service for a specific vessel.

\section{Acknowledgment}

This work was undertaken in collaboration between the University of Tasmania, Revolution Design and International Catamarans Tasmania (INCAT) through the support of the Australian Research Council. The work of Dr Jalal Rafie Shahraki in the development and production of the hydroelastic segmented model is also gratefully acknowledged.

\section{Declaration of conflicting interests}

The authors declare that there is no conflict of interest.

\section{References}

1. Davis MR and Holloway DS. The influence of hull form on the motions of high speed vessels in head seas. Ocean Engineering. 2003; 30: 2091-115.

2. Fang C-C and Chan H-S. Investigation of seakeeping characteristics of high-speed catamarans in waves. Journal of Marine Science and Technology. 2004; 12: 7-15. 
3. Rafie Shahraki J. The influence of hull form on the slamming behaviour of large high speed catamarans. PhD Thesis, University of Tasmania, 2014.

4. Matsubara S, Thomas G, Davis MR, Holloway DS and Roberts T. Influence of centrebow on motions and loads of high-speed catamarans. Proceedings of the 11th International Conference on Fast Sea Transportation, Hawaii, USA. 2011, p. 661-8.

5. Davis MR and Whelan JR. Computation of wet deck bow slam loads for catamaran arched cross sections. Ocean Engineering. 2007; 34: 2265-76.

6. Lavroff J, Davis MR, Holloway DS and Thomas G. Wave slamming loads on wave-piercer catamarans operating at high-speed determined by hydro-elastic segmented model experiments. Marine Structures. 2013; 33: 120-42.

7. Thomas G, Winkler S, Davis M, et al. Slam events of high-speed catamarans in irregular waves. Journal of Marine Science and Technology. 2011; 16: 8-21.

8. Thomas GA, Davis MR and Holloway DS. The whipping vibration of large high speed catamarans. International Journal of Maritime Technology. 2003; 145: 289-304.

9. Lavroff J and Davis MR. Slamming kinematics, impulse and energy transfer for wavepiercing catamarans. Journal of Ship Research. 2015; 59: 145-61.

10. Shahraki JR, Davis MR, Shabani B, et al. Mitigation of Slamming of Large Wave-Piercing Catamarans. The 30th Symposium on Naval Hydrodynamics. Hobart, Tasmania, Australia2014, p. 113.

11. Lavroff J. The Slamming and Whipping Vibratory Response of a Hydroelastic Segmented Catamaran Model. PhD Thesis, University of Tasmania, 2009.

12. Whelan J. Wetdeck slamming of high-speed catamarans with a centre bow University of Tasmania, 2004.

13. ITTC. Recommended Procedures and Guidelines : Seakeeping Experiments, 7.5-02-07. 02.1.

2011.

14. Esteban S, Giron-Sierra JM, Recas J and De la Cruz JM. Frequency-domain analysis for prediction of seasickness on ships. Marine Technology. 2005; 42: 192-8.

15. O'Hanlon JF and McCauley ME. Motion sickness incidence as a function of the frequency and acceleration of vertical sinusoidal motion. DTIC Document, 1973.

16. Piscopo V and Scamardella A. The overall motion sickness incidence applied to catamarans. International Journal of Naval Architecture and Ocean Engineering. 2015; 7: 655-69.

17. Ochi MD and Bonilla-Norat J. Pressure-velocity relationship in impact of a ship model dropped onto the water surface and in slamming in waves. DTIC Document 1970.

18. French BJ, Thomas GA and Davis MR. Slam occurrences and loads of a high-speed wave piercer catamaran in irregular seas. Institution of Mechanical Engineers Proceedings Part M: Journal of Engineering for the Maritime Environment. 2013: 1-13.

19. Lavroff J, Davis MR, Holloway DS, Thomas GA and McVicar JJ. Wave impact loads on wave-piercing catamarans. Ocean Engineering. 2017; 131: 263-71. 


\section{Figures}

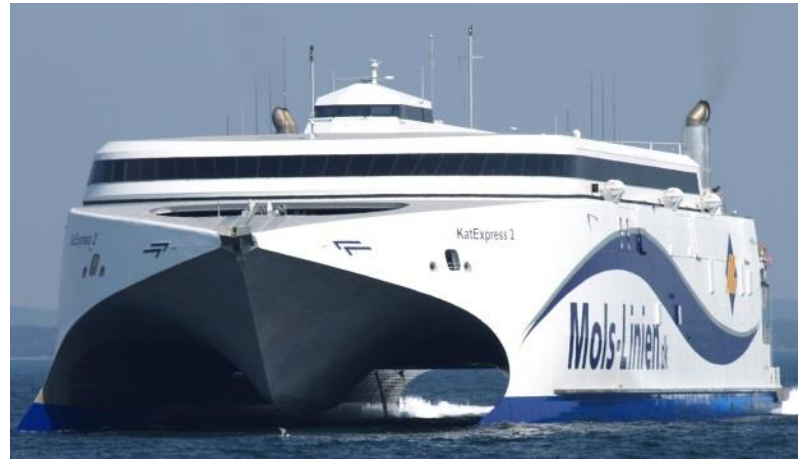

Figure 1. Incat Tasmania wave piercer catamaran with above water centre bow (http://www.incat.com.au/).

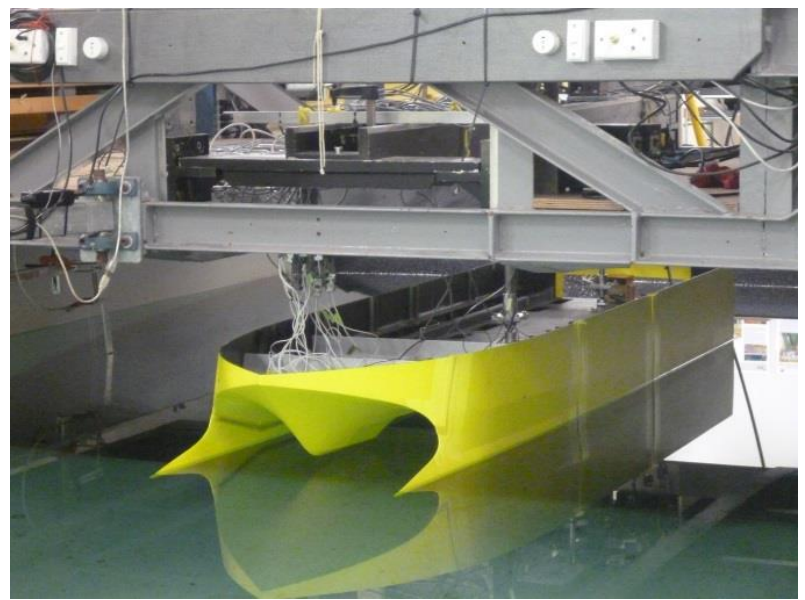

Figure 2. The $2.5 \mathrm{~m}$ catamaran model (HSM02) of the 112-m INCAT wave piercing catamaran. 


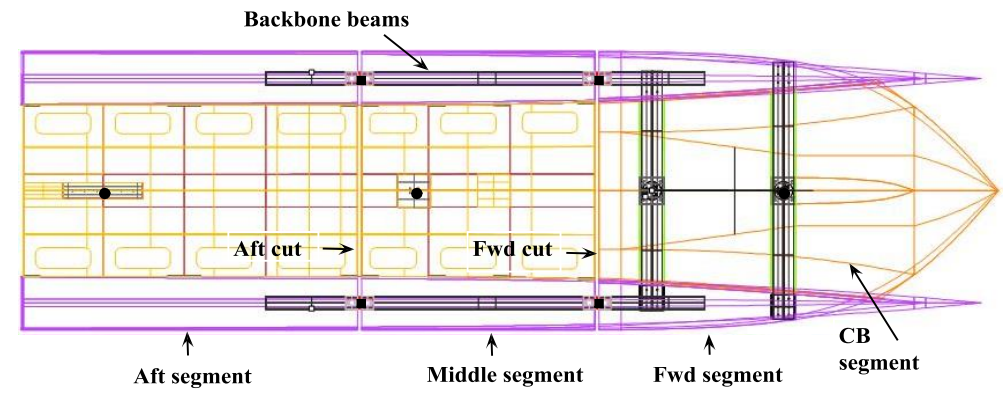

Figure 3. Schematic plan view of the segmented catamaran model (HSM02).

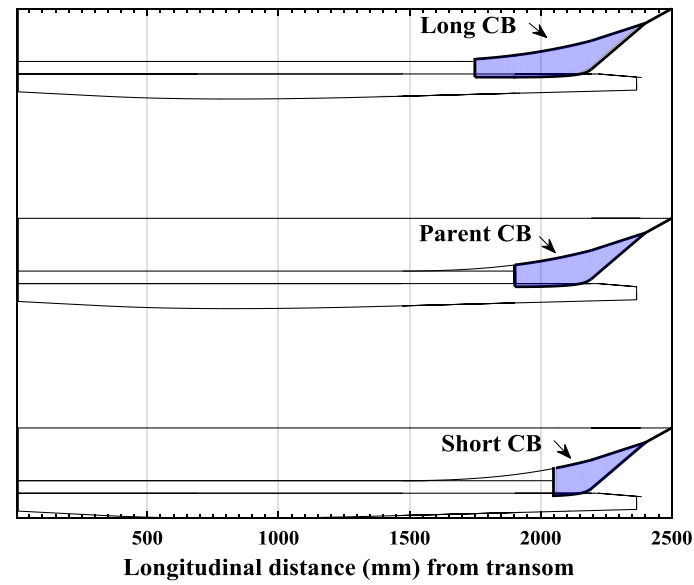

Figure 4. Schematic representation of the long, parent and short centre bows of the $2.5 \mathrm{~m}$ segmented catamaran model. 


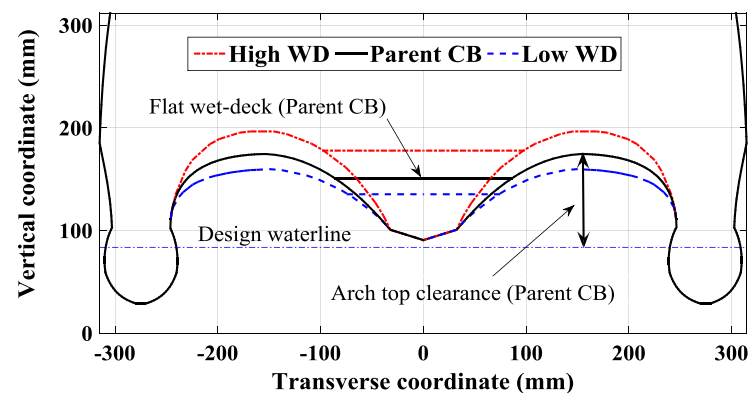

Figure 5. Sectional representation at longitudinal position $1892 \mathrm{~mm}$ ahead of the transom for the $2.5 \mathrm{~m}$ segmented model with the high, parent and low tunnel height centre bow and wet-deck configurations.

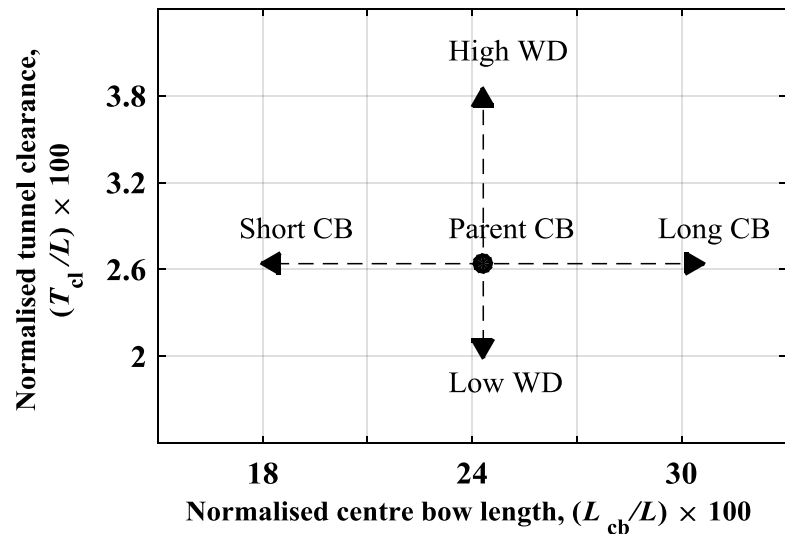

Figure 6. Tunnel clearance and centre bow length normalised by overall length for different centre bow configurations. 


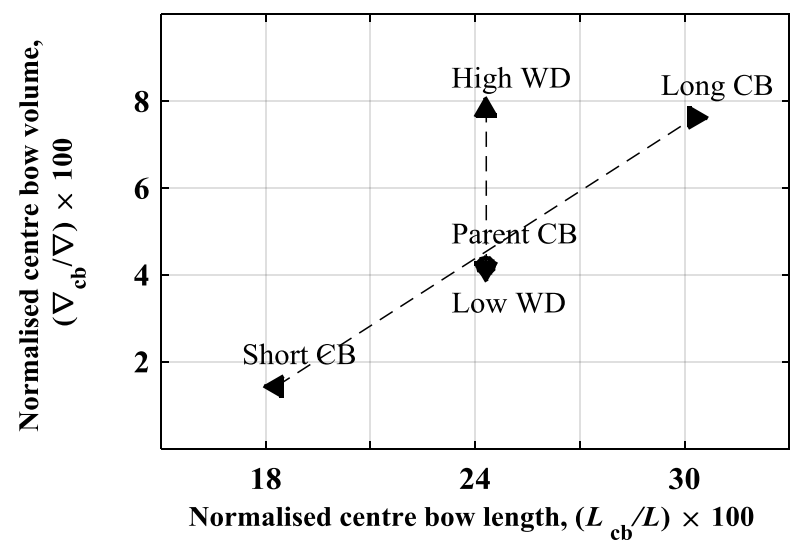

Figure 7. Normalised centre bow volume as a function of normalised centre bow length for different centre bow configurations.

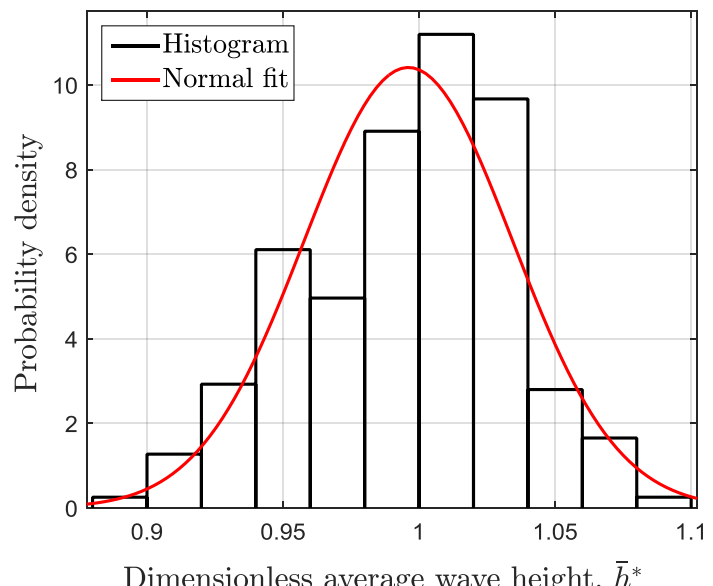

Figure 8. Histogram and a normal fit of dimensionless average wave height. 


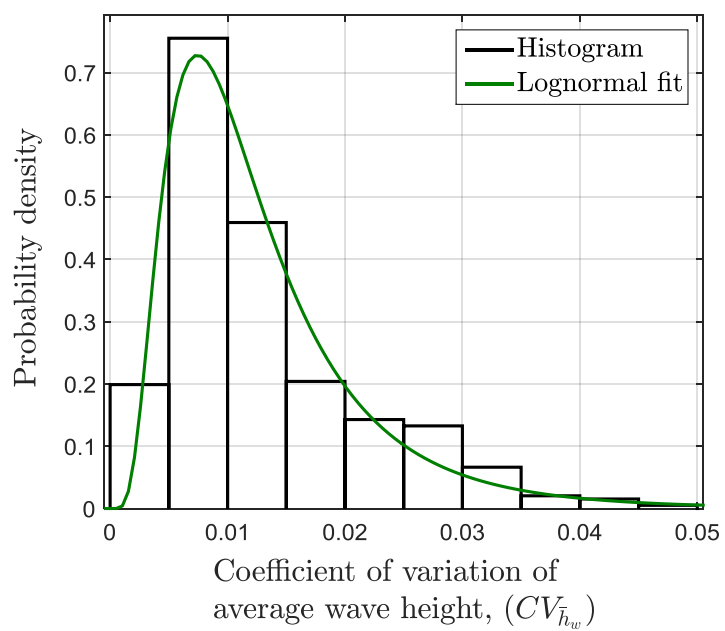

Figure 9. Histogram and a lognormal distribution fit of coefficient of variation of the average wave height. 

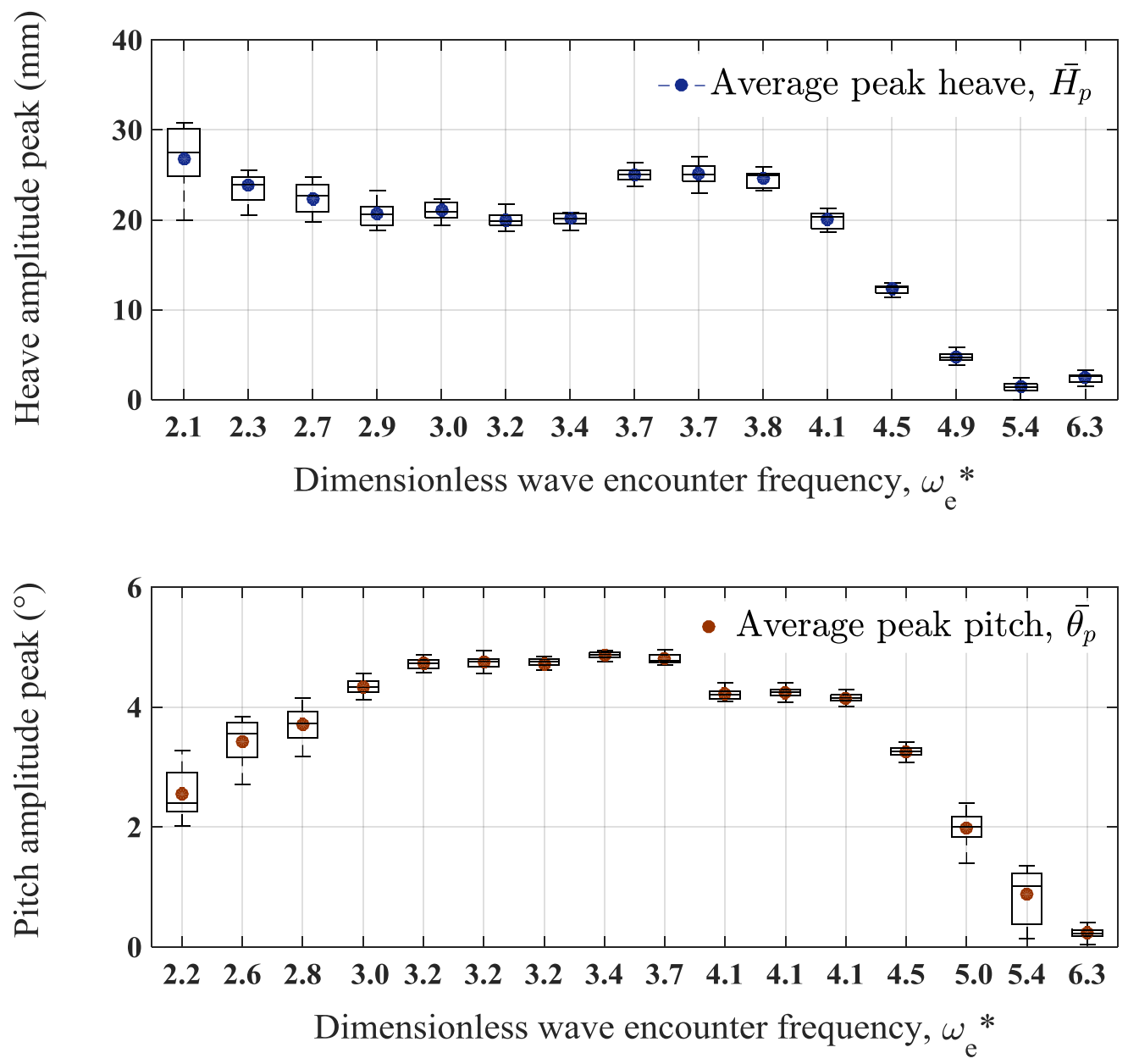

Figure 10. Variability in heave (top) and pitch (bottom) peaks for the model with parent centre bow at a speed of $2.89 \mathrm{~m} / \mathrm{s}$ in $60 \mathrm{~mm}$ wave height. 


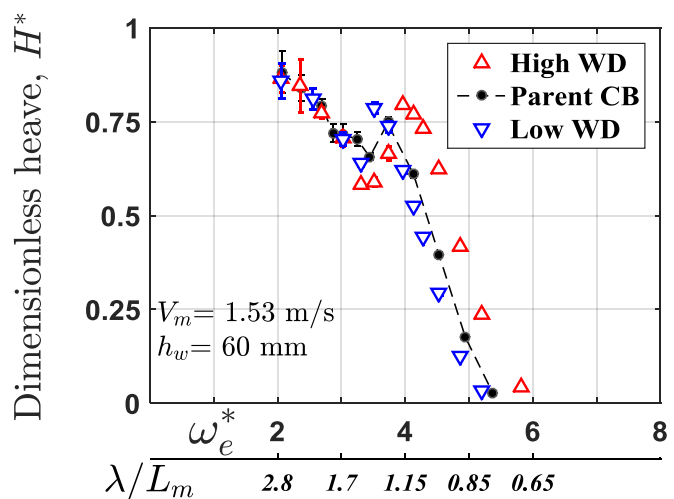

(a)

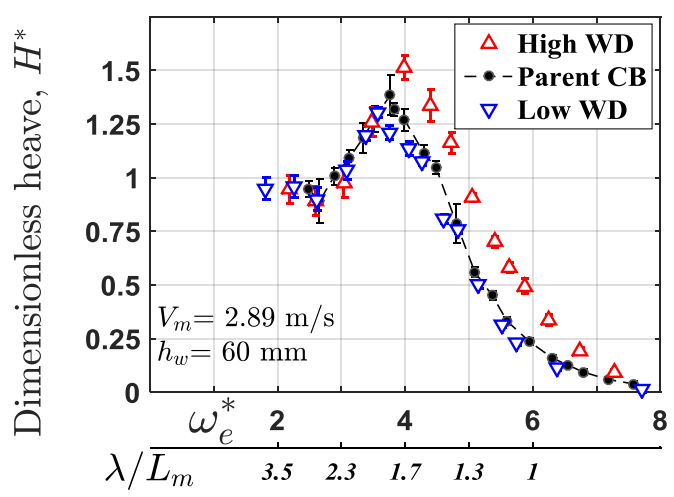

(c)

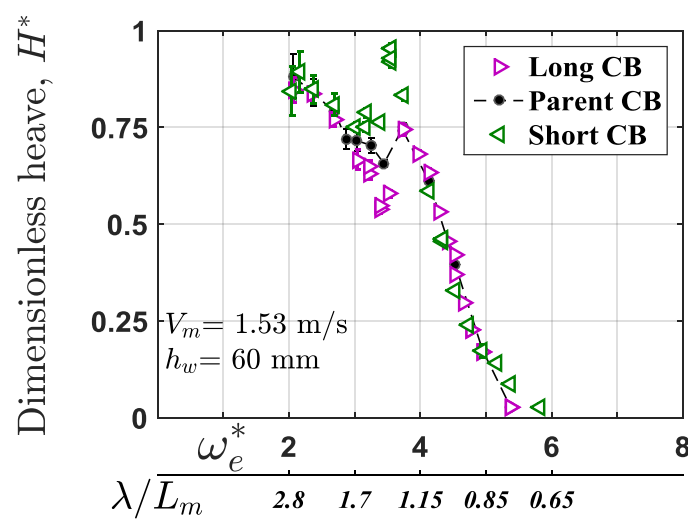

(b)

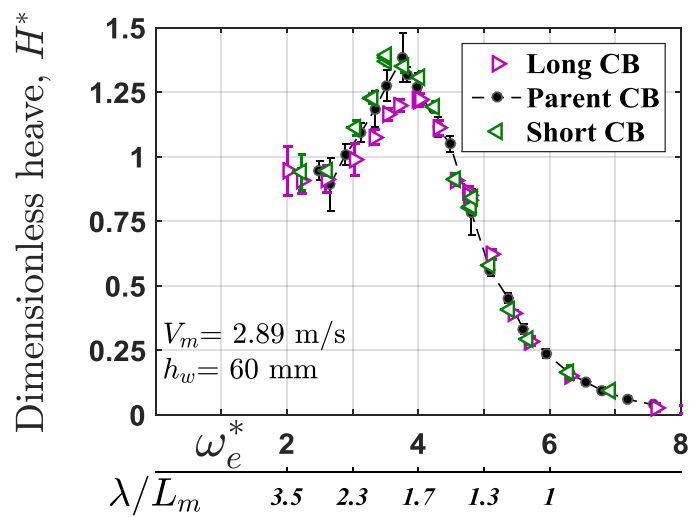

(d)

Figure 11. Dimensionless heave responses of the catamaran model with different centre bow length and wetdeck configurations at different speeds. 


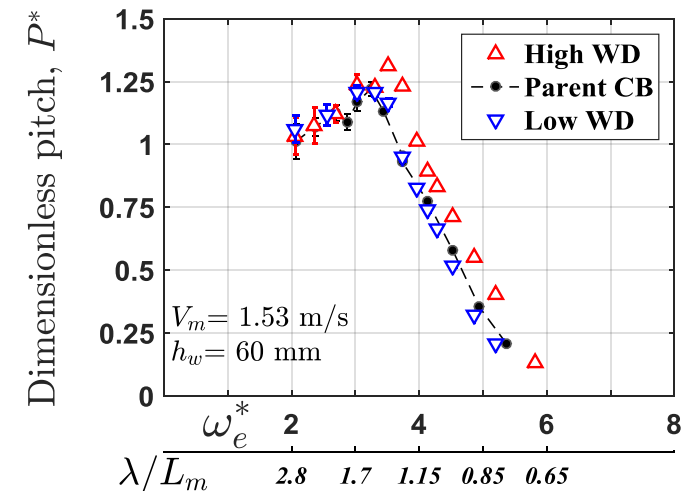

(a)

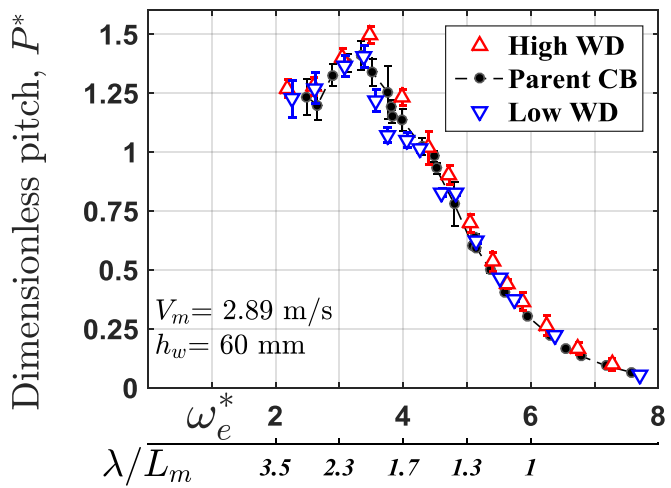

(c)

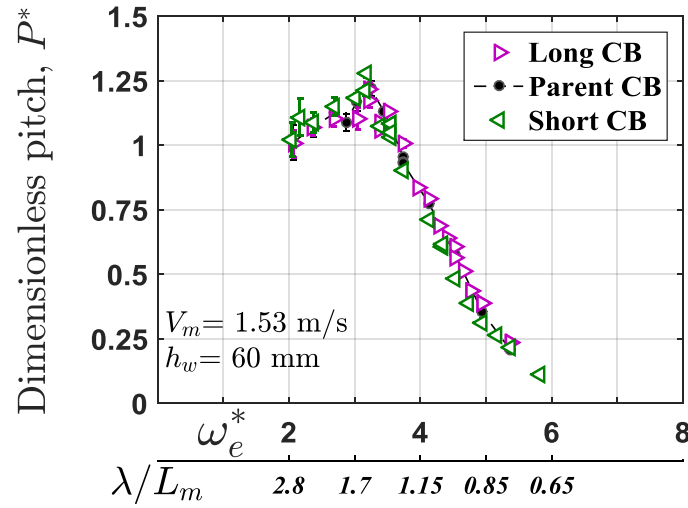

(b)

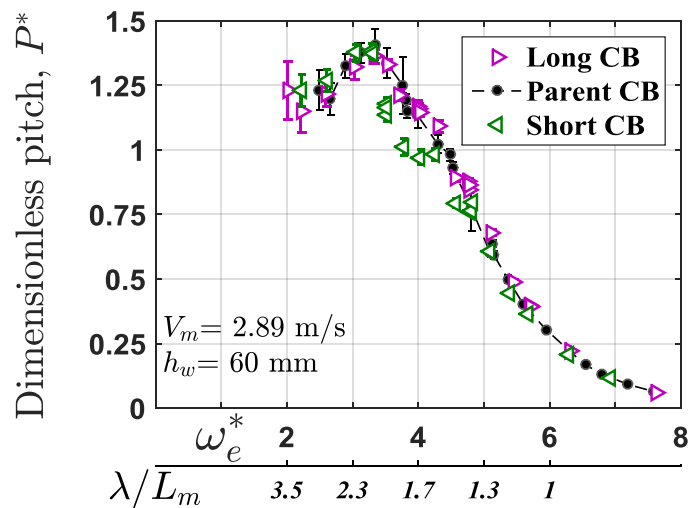

(d)

Figure 12. Dimensionless pitch responses of the catamaran model with different centre bow length and wetdeck configurations at different speeds. 


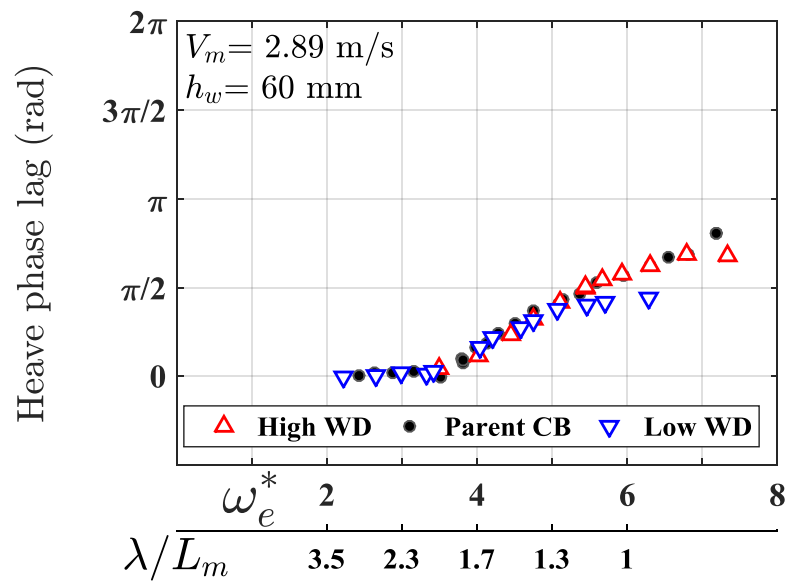

(a)

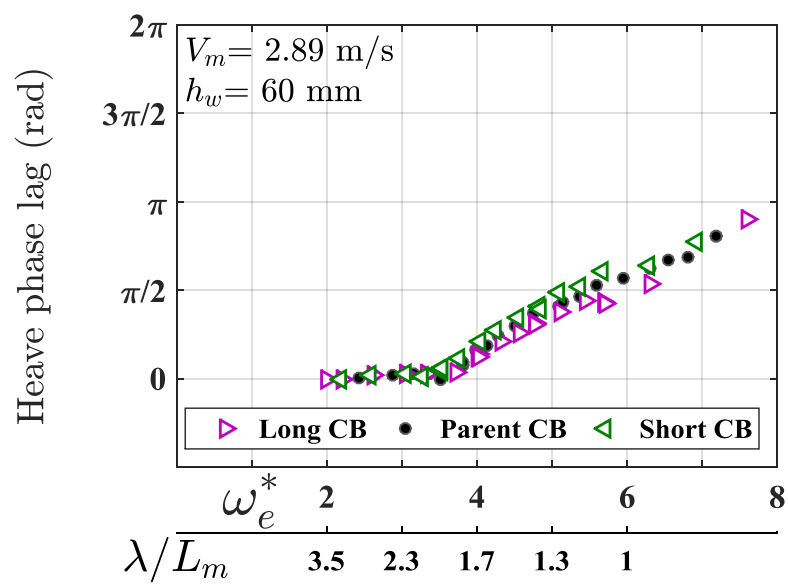

(b)

Figure 13. Heave phase lag relative to wave elevation at LCG, obtained for the catamaran model with different centre bows and wet-deck configurations at a speed of $2.89 \mathrm{~m} / \mathrm{s}$ in $60 \mathrm{~mm}$ wave height. 


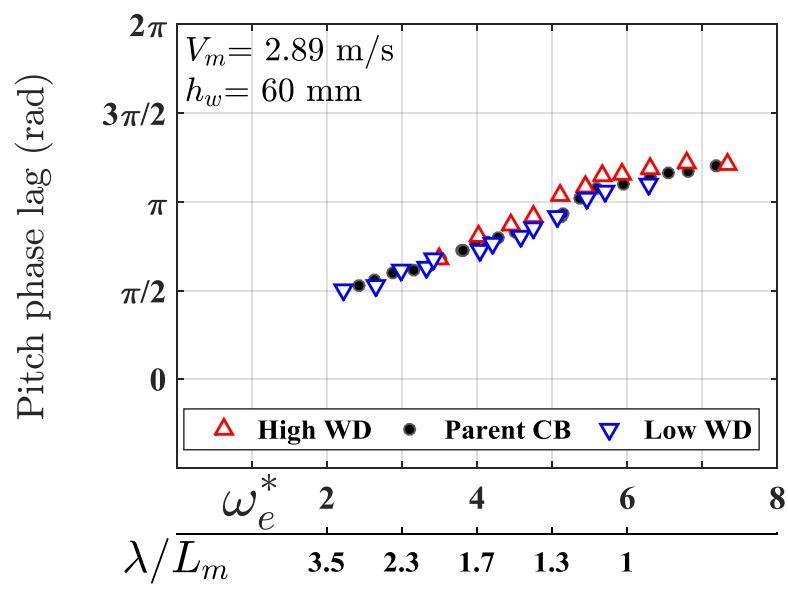

(a)

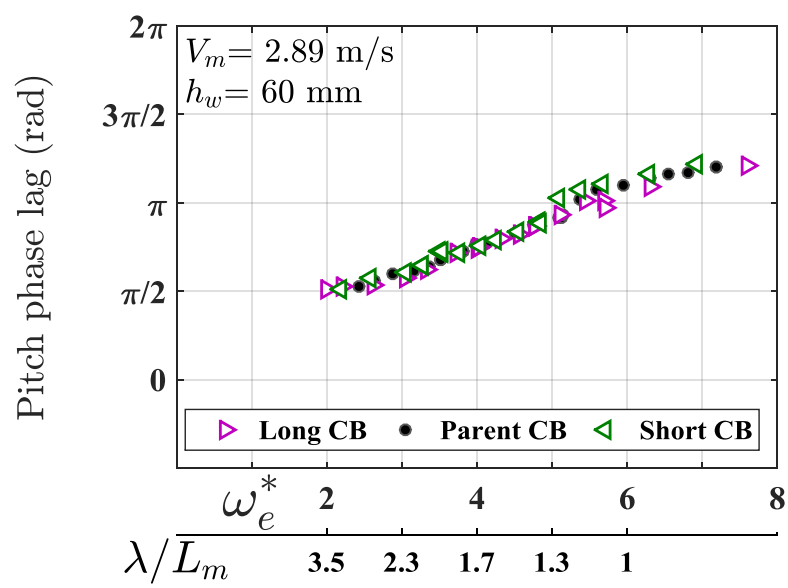

(b)

Figure 14. Pitch phase lag relative to wave elevation at LCG, obtained for the catamaran model with different centre bows and wet-deck configurations at a speed of $2.89 \mathrm{~m} / \mathrm{s}$ in $60 \mathrm{~mm}$ wave height. 


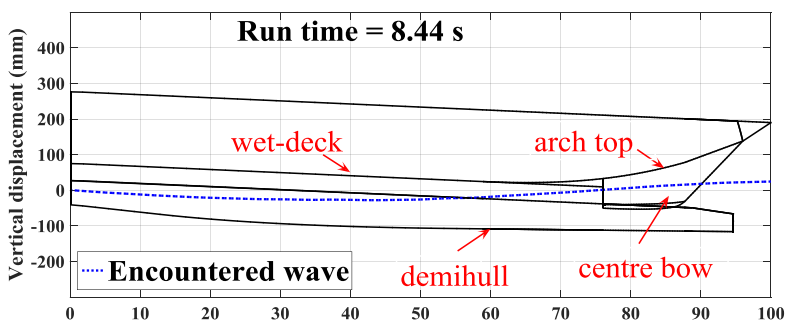

(a)

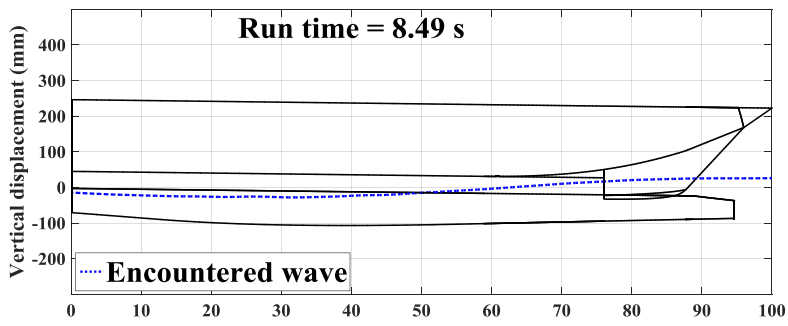

(b)

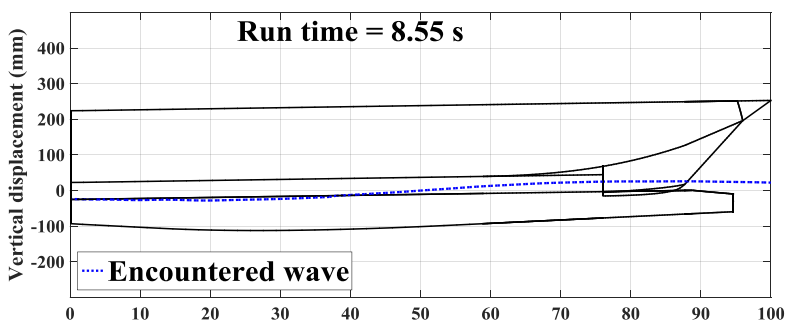

(c) 


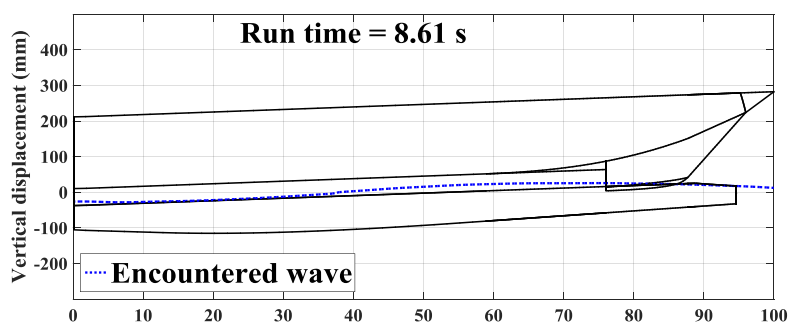

(d)

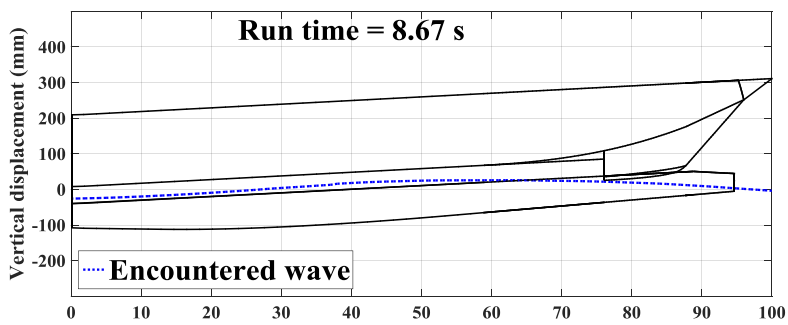

(e)

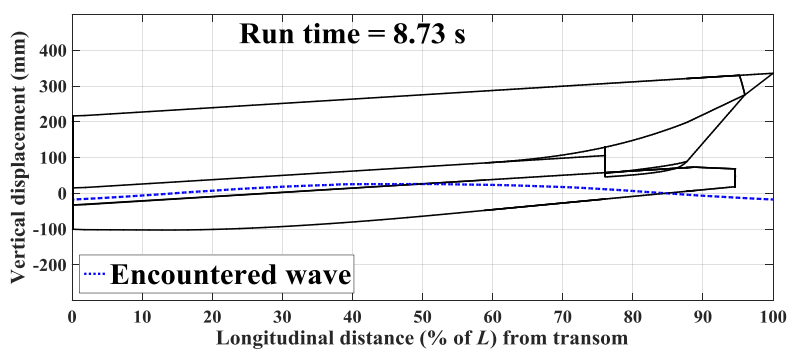

(f)

Figure 15. Overall catamaran model motions from time $t=8.44 \mathrm{~s}$ to $8.73 \mathrm{~s}$ in one cycle of waves at $\omega_{e}^{*}=4.5$, $h_{w}=60 \mathrm{~mm}$ and $V_{m}=2.89 \mathrm{~m} / \mathrm{s}$. 


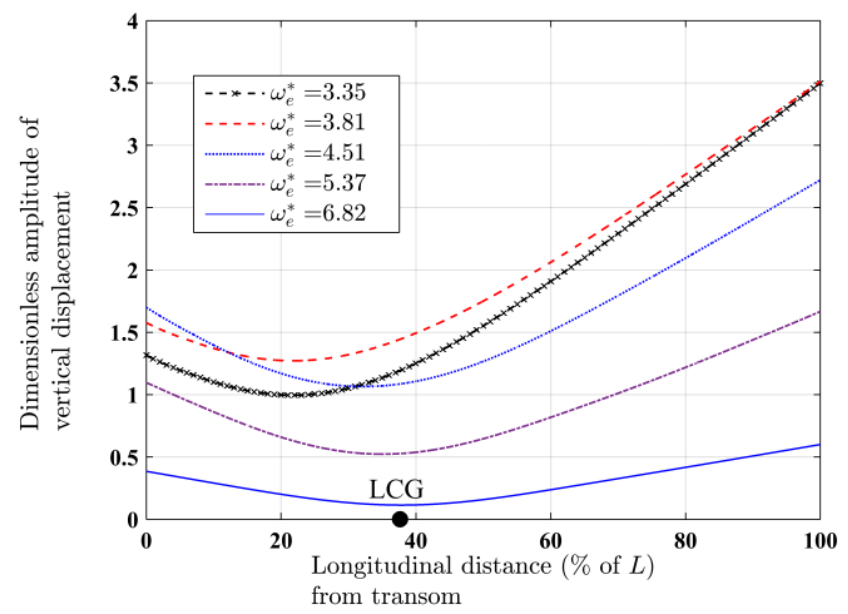

Figure 16. Distribution of dimensionless vertical displacement of the catamaran model along the model

length at various dimensionless wave encounter frequencies for the parent CB configuration at a speed of $2.89 \mathrm{~m} / \mathrm{s}$ in $60 \mathrm{~mm}$ wave height. 


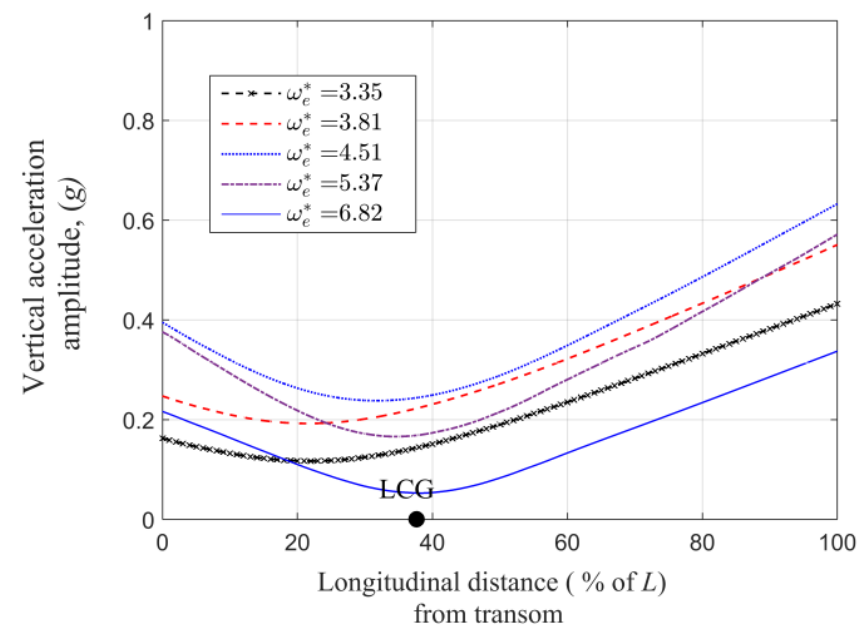

Figure 17. Distribution of vertical acceleration amplitude of the catamaran model along the model length at various dimensionless wave encounter frequencies for the parent $C B$ configuration at a speed of $2.89 \mathrm{~m} / \mathrm{s}$ in $60 \mathrm{~mm}$ wave height. 


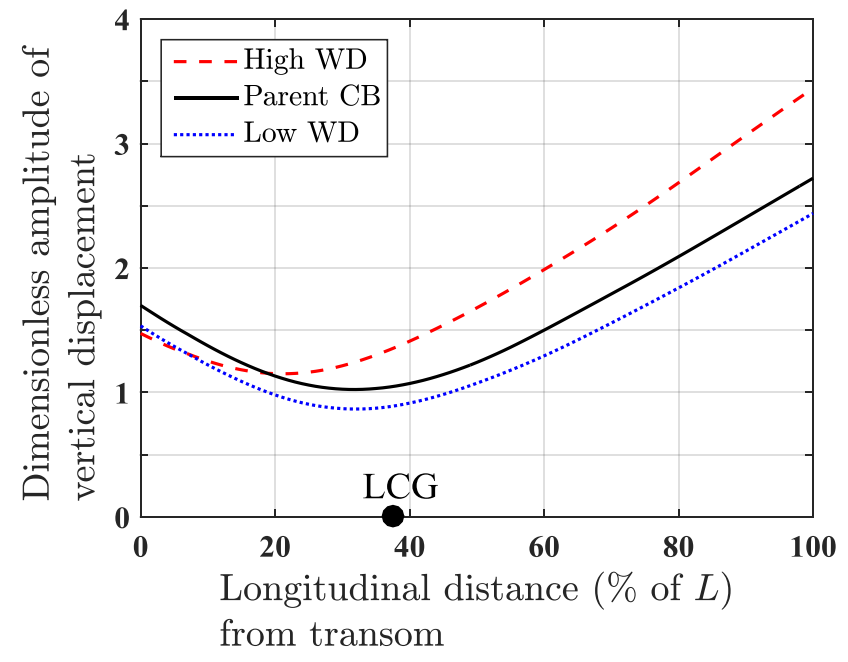

(a)

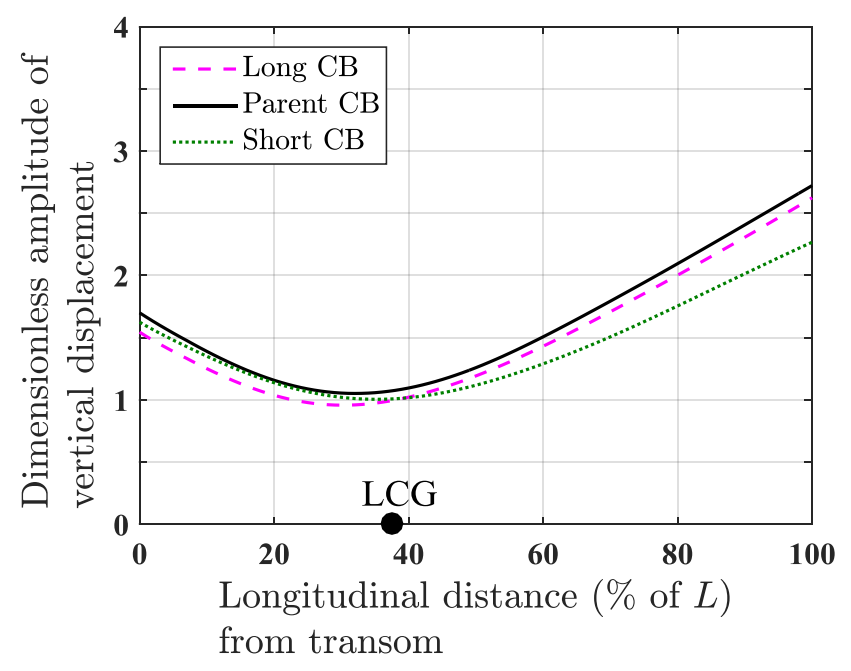

(b)

Figure 18. Distribution of dimensionless vertical displacement of the catamaran model along the model length for different $C B$ configurations at $\omega_{e}^{*} \cong 4.5$, at a speed of $2.89 \mathrm{~m} / \mathrm{s}$ and in $60 \mathrm{~mm}$ wave height. 


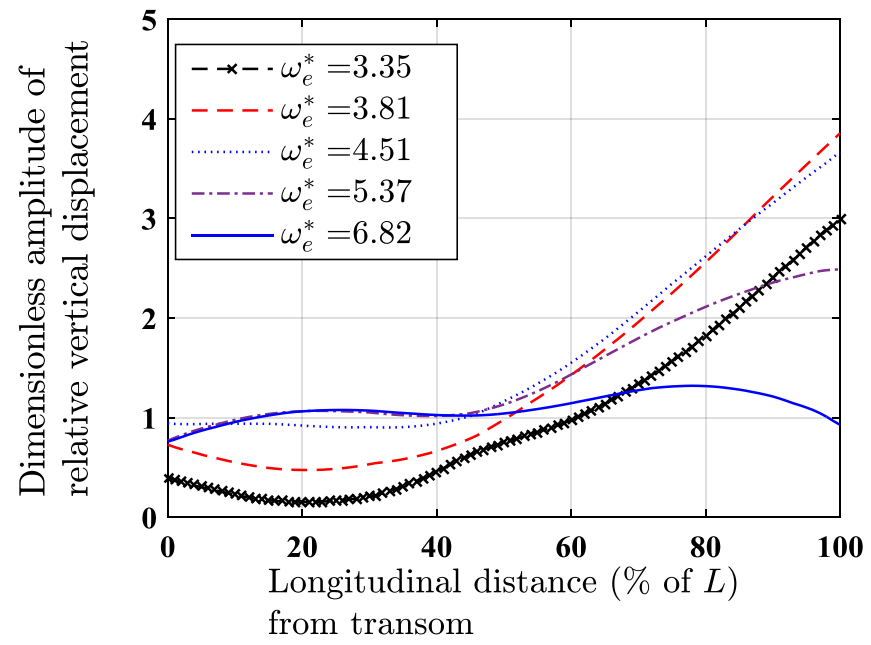

Figure 19. Distribution of dimensionless relative vertical displacement of the catamaran model along the model length at various dimensionless wave encounter frequencies for the parent $\mathrm{CB}$ configuration at a speed of $2.89 \mathrm{~m} / \mathrm{s}$ in $60 \mathrm{~mm}$ wave height. 


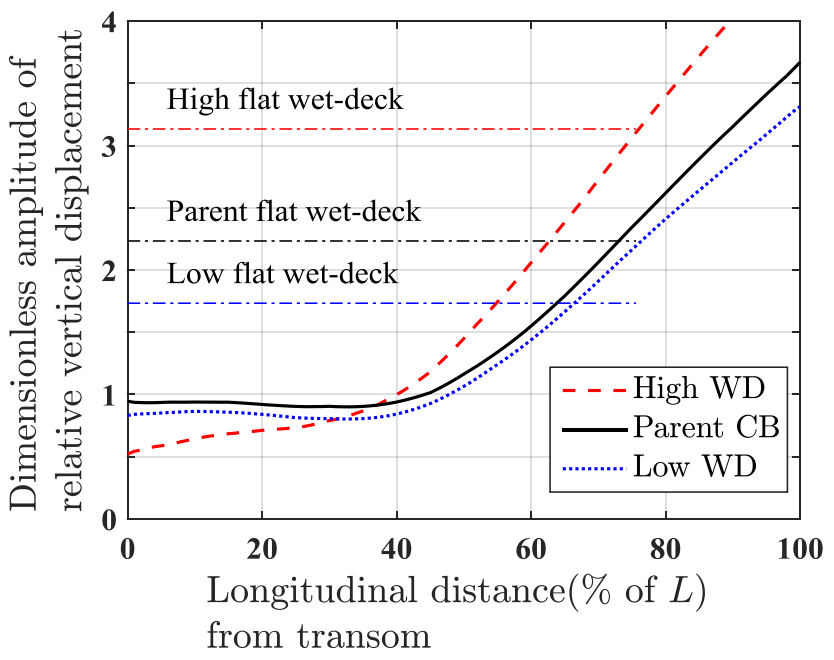

(a)

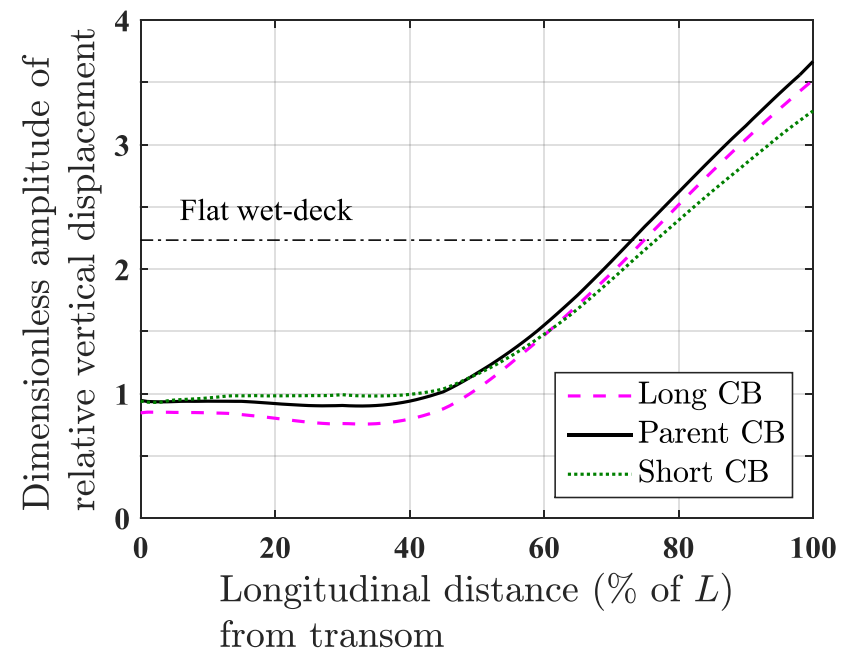

(b)

Figure 20. Distribution of dimensionless relative vertical displacement of the catamaran model along the model length for different $C B$ configurations at $\omega_{e}^{*} \cong 4.5$, at a speed of $2.89 \mathrm{~m} / \mathrm{s}$ and in $60 \mathrm{~mm}$ wave height. 